\title{
Spectrum of Acute Non Traumatic Diffuse Secondary Peritonitis in the Tropics
}

\author{
Mamadou Traore*, Kouakou Ibrahim Anzoua, Kouamé Bernadin Kouakou, Ismael Kalou Leh Bi, \\ Ahou Bernadette N'dri, Aka Gerald Kakou, Serge Amos Ekra, Blaise Amos Kouakou, Inza Bamba, \\ Roger Lebeau, Bamourou Diane
}

General and Digestive Surgery Department, Bouaké Teaching Hospital, Bouaké, Republic of Côte d'Ivoire

Email: *traorefallstam2000@yahoo.fr

How to cite this paper: Traore, M., Anzoua, K.I., Kouakou, K.B., Bi, I.K.L., N'dri, A.B., Kakou, A.G., Ekra, S.A., Kouakou, B.A., Bamba, I., Lebeau, R. and Diane, B. (2020) Spectrum of Acute Non Traumatic Diffuse Secondary Peritonitis in the Tropics. Surgical Science, 11, 89-98.

https://doi.org/10.4236/ss.2020.115012

Received: April 8, 2020

Accepted: May 19, 2020

Published: May 22, 2020

Copyright $\odot 2020$ by author(s) and Scientific Research Publishing Inc. This work is licensed under the Creative Commons Attribution International License (CC BY 4.0).

http://creativecommons.org/licenses/by/4.0/

(c) (i) Open Access

\section{Abstract}

Background: Peritonitis is one of the most common surgical emergency in tropical countries. It is still a significant cause of mortality and morbidity. This study aimed to describe the aetiology of acute non traumatic diffuse secondary peritonitis (ANDSP) and to report the outcome after treatment. Material and Methods: A retrospective survey of patients with ANDSP was carried out from January 2007 to December 2016 in the Digestive and General Surgery Service of Bouaké Teaching Hospital in the central part of Côte d'Ivoire. The hospital is a tertiary referral centre and serves urban and rural population from Bouakés agglomeration but also from the whole central and northern parts of the country. During the study period, all patients found to have at laparotomy ANDSP were included. The analysed variables include epidemiologic charts, clinical presentation, cause of peritonitis, surgical treatment, postoperative outcome and prognostic factors. Results: Over the studied period 626 cases of ANDSP were operated on. The main aetiologies were gastroduodenal peptic ulcer perforation $(\mathrm{n}=252,41.1 \%)$, typhoid ileal perforation $(n=207,33 \%)$ and appendicular peritonitis $(n=123,19.6 \%)$. The mean duration of hospital stay was $13.8 \pm 9.6$ days (range $8-87$ days). The length of hospital stay was significantly influenced by postoperative complications $(23.5 \pm 5.4$ days versus $10.8 \pm 2.7$ days $\mathrm{P}=0.000000)$. Two hundred and sixty one postoperative complications were recorded in 242 patients (38.6\%) with wound infection being the commonest postoperative complication. A repeat laparotomy was indicated in 73 patients. Eigthy $(n=80)$ patients died (mortality 11.2\%). Risk factors for death were hemodynamic shock, ASA $>$ II, Age $\geq 60$ years, M PI $>29$ and digestive sutures performed in septic environment below the transverse mesocolon. Conclusion: The spectrum of aetiology of ANDSP in this tropical area is different from the one observed in the Western countries. Proper treatment of typhoid fever and amoebiasis can 
reduce the incidence of peritonitis. Early consultation together with adequate resuscitation and surgical management can improve the prognostic which still remains poor.

\section{Keywords}

Peritonitis, Appendicitis, Typhoid Perforation, Gastrointestinal Ulcer

Perforation, Prognostic

\section{Introduction}

Acute peritonitis is one of the most common surgical emergencies encountered by surgeon the world over. On the basis of source and nature of microbial contamination acute peritonitis is classified as primary, secondary and tertiary [1]. Acute secondary peritonitis is the most common form of peritonitis encountered; it can be also classified as traumatic or non traumatic. It is known that non-trauma related conditions are still responsible for a high number of in-hospital deaths and require specific attention, especially in Africa [2]. Acute non traumatic diffuse secondary peritonitis (ANDSP) is one of these conditions whose treatment is highly demanding. Though combination of improved surgical techniques, antimicrobial therapy, and intensive care support has improved its outcome, this non trauma related condition still carries a heavy mortality and morbidity rates which remain closely related to aetiology [3] [4]. The causes of generalized peritonitis vary widely from one setting to another. In western countries the risk factors for ANDSP are outnumbered by duodenal ulcer perforations, appendicular peritonitis, and infectious complications of colonic diverticulosis, colonic cancer and biliopancreatic affections [5] [6] [7] [8]. On the other hand in Africa poor environmental hygiene conditions favour the development of infectious (typhoid fever) and parasitic (amoebiasis) diseases whose peritoneal complications are the cause of severe peritonitis. This leads us to predict a different pattern of aetiology of ANDSP according to the areas. The objective of this work was therefore to describe the aetiology of ANDSP and to report the outcome after treatment in a tropical environment also characterized by poor technical background, limited access to health insurance, intensive care unit.

\section{Subjects and Method}

A retrospective survey of patients with ANDSP was carried out in the Digestive and General Surgery Service of Bouaké Teaching Hospital in the central part of Côte d'Ivoire from January 2007 to December 2016. Bouaké Teaching Hospital is a 283-bed urban public hospital. The hospital is a tertiary referral centre and serves urban and rural population from Bouakés agglomeration but also from the whole central and northern parts of the country. As patients came late to hospital signs and symptoms were typical and we were able to make a clinical 
diagnosis of peritonitis in all patients. An erect chest X-ray was requested and performed in all patients and revealed a pneumoperitoneum in $35.8 \%$ of cases. All patients found to have peritonitis as a result of intraabdominal abscess rupture, perforation or necrosis of any part of gastrointestinal tract were included in the study. Diffuse peritonitis was defined as any intra-abdominal infection extending beyond the transverse mesocolon [9]. All patients with primary peritonitis defined as diffuse peritonitis with no identifiable source of infection during surgical exploration, anastomotic dehiscence, traumatic perforation of gastrointestinal tract, localized peritonitis, suspected peritonitis for whom a laparotomy was not performed were exluded. The cases were studied in term of patient's characteristics, operative findings and postoperative outcome. The characteristics of the peritonitis were classified according to the MPI (Mannheim peritonitis index) which has been extensively used to predict the outcome of various forms of peritonitis [10]. The severity of complications was graded according to the Clavien-Dindo classification [11]. Only adverse events occurring during the same admission were considered. Factors involved in death had been looked for among parameters such as age, sex, ASA class (American Society of Anaethesiologists class) [12], Mannheim peritonitis index [11], preoperative hemodynamic shock (systolic blood pressure inferior to $100 \mathrm{~mm} \mathrm{Hg}$ ) and the surgical procedure whenever small or large bowel was the cause of peritonitis as it was either perforated or necrosis or both. For the statistic analysis, we used the X2 test for the qualitative variables. Student's test was used for quantitative variables and for the comparison of averages. In all tests, $p$ value $<0.05$ was considered to be statistically significant.

\section{Results}

\section{Patient's characteristic}

Out of 3374 patients operated on between January 2007 and December 2016, 626 patients [ 474 men $(75.7 \%)$ and 152 women (24.3\%)] suffered from ANDSP that is a prevalence of $18.5 \%$. With this figure, ANDSP holds the 3rd position of the indications of non traumatic emergency laparotomies after acute appendicitis $(\mathrm{N}=1414,41.9 \%)$ and acute intestinal occlusions $(\mathrm{n}=636,18.8 \%)$. The patients' mean age was $36.9 \pm 18.3$ years (ranges $17-91$ years). Ninety $(\mathrm{n}=90$ $20.9 \%)$ patients were age 60 years and above. The patients had a history of non explored epigastric pain $(n=66)$, of diarrhoea $(n=88)$, previous laparotomy $(n$ $=8)$, positive history of non-steroidal anti-inflammatory consumption $(\mathrm{n}=76)$ and permanent stress as they were living in a war zone $(\mathrm{n}=80)$. Eigtheen patients kept the Ramadan fast. Seventy nine patients were heavy smokers, smoking 15 - 45 cigarettes per day.

\section{Aetiologic aspects}

The delay between onset of symptoms and admission ranged from 1 to 30 days with a mean of $4.9 \pm 3.9$ days. That delay was above 24 hours (one day) in 578 patients $(92.3 \%)$. At the admission, 134 patients (21.4\%) were in a haemo- 
dynamic shock. Widal's test and the amoebian serology were positive respectively in 136 and 06 patients; the stool culture revealed Salmonella typhi in 35 patients. According to ASA class, 32 patients were classified ASA I, 275 patients were classified ASA II, 242 patients were classified ASA III and 77 patients were classified ASA IV. When assessing the severity of the peritonitis, we divided our patients into two groups: those with a MPI $\leq 29(\mathrm{n}=567)$, and those with MPI > $29(n=59)$. Above the transverse mesocolon, gastro-duodenal peptic ulcer perforation $(\mathrm{n}=252)$ was the most common cause of peritonitis whereas appendicular peritonitis $(\mathrm{n}=123)$ and typhoid related perforations of the ileum $(\mathrm{n}=$ 207) outnumbers the aetiologies below the transverse mesocolon (Table 1). All typhoid related perforations of the small bowel were located in the last $150 \mathrm{~cm}$ of the ileum.

\section{Therapeutic aspects}

The patients had preoperative adequate resuscitation then underwent exploratory laparotomy. All patients with a suspicion of diffuse peritonitis had an antibiotic regimen started in the emergency department. They received a combination of cephalosporin and metronidazole as soon as the diagnosis was made. An aminoglycoside was added in the postoperative period except for patients suffering from renal failure or those whose urine outpout was less than $500 \mathrm{ml} / 24$ hours, gastro-duodenal peptic ulcer perforation or liver amoebian abcess rupture $(\mathrm{n}=342)$. The mean duration of antibiotic therapy was 9.5 days (range $7-12$ days) in patient with no postoperative complication. At surgery the source of peritoneal contamination was sougth for and controlled with adequate procedure. So, above the transverse mesocolon patients with gastroduodenal peptic ulcer perforation were managed by simple closure and omental patch. Patients suffering from gallbladder necrosis and rupture of spleen abscess underwent respectively cholecystectomy $(n=6)$ and splenectomy $(n=1)$. The remaining 10 patients suffering from ruptured of amoebian liver abscess were managed by simple debridement and pus evacuation.

Below the transverse mesocolon, appendicular peritonitis was treated by appendicectomy. On the small bowel, stoma with or without bowel resection was

Table 1. Distribution of patients according to lesions.

\begin{tabular}{cccc}
\hline Organ & Lesion & Number & Percentage \\
\hline Stomach & Ulcer perforation & 246 & 40.2 \\
Liver & Amoebian abscess & 10 & 1.6 \\
Duodenum & Ulcer perforation & 6 & 0.9 \\
Spleen & Abscess rupture & 1 & 0.1 \\
Gall bladder & Necrosis & 6 & 0.9 \\
Appendicitis & Perforation, necrosis & 123 & 19.6 \\
Adnexal & Abscess rupture & 14 & 2.2 \\
ileum & Typhoic perforation & 207 & 33 \\
Colon & Colic necrosis & 16 & 2.5
\end{tabular}


performed in $73.1 \%$ of cases $(\mathrm{n}=151)$ excision or bowel resection with immediate suture was performed in the remaining $26.9 \%$ of the cases $(n=56)$. On the colon, resection and Hartmann procedure was performed in all the cases $(\mathrm{n}=$ 16). When considering small bowel together with large bowel $(\mathrm{n}=223)$, a one stage procedure was performed in 151 patients (67.7\%) and a two stage procedure was performed in 72 patients (32.3\%). For gynaecological causes, we performed salpingoophorectomy $(n=14)$. The peritoneal cavity was then irrigated with warm normal saline and at least two drains were inserted before the abdomen was closed.

\section{Post operative outcome}

The mean duration of hospital stay was $13.8 \pm 9.6$ days (range 8- 87 days). The length of hospital stay was significantly influenced by postoperative complications [23.5 \pm 5.4 days (range $13-87$ days) versus $10.8 \pm 2.7$ days (range $8-14$ days $)(\mathrm{P}=0.000000)]$.

Two hundred and sixty one postoperative complications were recorded in 242 patients (38.6\%) with wound infection being the commonest postoperative complication as it occurred in 156 patients. Wound infection resulted in post operative evisceration in 21 patients (Table 2). Gastrointestinal fistula occurred in 46 patients; it closed with conservative strategies in 10 patients and resulted in postoperative peritonitis in 36 patients. A repeat laparotomy was indicated in 73 patients as they suffered from postoperative peritonitis $(n=36)$, postoperative evisceration $(n=21)$, subphrenic abscess $(n=6)$ and stoma necrosis $(n=10)$. Eigthy (80) patients, 13 of whom were re-operated on died (mortality 11.2\%). The cause of deaths was toxi-infectious shock. The age, surgical procedure, MPI greater than 29, ASA greater than II, delay in admission time and multiorgan failure are the mortality factors recognized $(\mathrm{P}<0.001)$ (Table 3$)$. According to the Clavien-Dindo classification, as shown in Table 4, when considering those who died (classified as grade $\mathrm{V}$ complication). The majority of patients developed a grade I complication.

Table 2. Distribution according postoperative complications.

\begin{tabular}{ccc}
\hline Type of complications & Complications & Number \\
\hline Surgery related complications & Wound infection & 156 \\
& Digestive fistulas & 46 \\
& Peristomial dermatitis & 16 \\
Stoma necrosis & 6 \\
Medical related complications & Subphrenic abscess & 10 \\
& Gluteal sloughs & 8 \\
& pneumopathies & 5 \\
\hline
\end{tabular}


Table 3. Risk factors for death.

\begin{tabular}{|c|c|c|c|}
\hline Parameters & Number & Deaths (percentage) & $P$ values \\
\hline Age $<60$ years & 536 & $32(6 \%)$ & $<0.001(\mathrm{~s})^{(3}$ \\
\hline Age $\geq 60$ years & 90 & $48(53.3 \%)$ & \\
\hline Hemodynamic shock & 134 & $60(44.8 \%)$ & $<0.001(\mathrm{~s})$ \\
\hline No Hemodynamic shock & 492 & $20(4.1 \%)$ & \\
\hline Male & 474 & $57(12 \%)$ & $0.5(\mathrm{NS})^{(4)}$ \\
\hline Female & 152 & $23(15.1 \%)$ & \\
\hline M PI $\leq 29$ & 567 & $47(8.3 \%)$ & $<0.001(S)$ \\
\hline M PI $>29$ & 59 & $33(5.9 \%)$ & \\
\hline $\mathrm{ASA} \leq \mathrm{II}$ & 319 & $12(3.8 \%)$ & $<0.001(S)$ \\
\hline ASA $>$ II & 307 & $68(22 \%)$ & \\
\hline Admission Time $\leq 24 \mathrm{H}$ & 48 & $1(2.1 \%)$ & $0.1399(\mathrm{NS})$ \\
\hline Admission Time $>24 \mathrm{H}$ & 578 & $79(13.7 \%)$ & \\
\hline Immediate anastomosis $^{(1)}$ & 72 & $33(45.8 \%)$ & $<0.001(S)$ \\
\hline Delayed anastomosis $^{(2)}$ & 151 & $8(5.3 \%)$ & \\
\hline
\end{tabular}

NB: (1): (2): immediate or delayed anastomosis on the jejuno-ileum (small bowel) and colon (large bowel) (3): Significant (4): Non Significant.

Table 4. The Clavien-Dindo classification of surgical complications.

\begin{tabular}{ccc}
\hline Grade & Number & Percent \\
\hline I & 164 & 50 \\
II & 14 & 4.3 \\
III & 70 & 21.3 \\
IV & 00 & 0.0 \\
V & 80 & 24.4 \\
Total & 328 & 100 \\
\hline
\end{tabular}

\section{Discussion}

\section{Study limits}

This study aimed to describe the aetiology of ANDSP and to report the outcome after treatment in a tropical environment. The diversity of surgical team could have influenced post operative result. Also nutritional status of patients was not assessed though they were in bad condition owing to late presentation to hospital. Finally, no peritoneal pus sample was collected for bacteriologic analysis.

\section{Aetiologic aspects}

Peritonitis remains a frequent emergency in abdominal surgery with a prevalence of $18.5 \%$ in our practice. It holds the $3^{\text {rd }}$ position after acute appendicitis and acute intestinal occlusions. This high prevalence of peritonitis has been also reported [13] [14] [15]. The most common aetiologies in our study were gastro- 
duodenal peptic ulcer perforation, typhoic related perforation of the ileum and appendicular peritonitis. These data are in conformity with those from several developing countries [4] [16] [17] [18]. The spectrum of aetiology of peritonitis found in this study is different from that of the western authors [5] [8] [15] [19]. It is determined by the peritoneal complications of infectious or parasitic diseases (typhoid fever, amoebiasis) which are still rampant in the developing countries [16] [20] [21]. This aetiologic spectrum is also influenced by socio-cultural and religious beliefs which lead to the practice of fast. Gastric or duodenal perforations during fast periods are consequences of such practices. In this study gastroduodenal perforation secondary to gastroduodenal peptic ulcer was the most frequent aetiology of peritonitis. This in contrary to a previous study conducted in the same hospital which showed appendicular peritonitis to be the most frequent aetiology [22]. Unlike to Yadav and Garg study, we didn't found bowel tubercular perforation in our study although tuberculosis is a frequent disease in our environment [19]. Late presentation was a major concern in this study and we reported delays as long as 30 days. The absence of modern diagnostic tools in settings with limited technical background cannot be considered a major problem as diffused peritonitis can generally be diagnosed or at least suspected on purely clinical grounds. Delay in consultation was quasi constant in this study maybe because people consider the traditional doctor as first resort, but also because of ignorance, fear of hospital, lack of mean or absence of health insurance [9] [13].

\section{Therapeutic aspects}

The aim of the surgical treatment is to eradicate the source of peritoneal contamination with adequate procedure [19] [23] [24] [25] [26]. According to the aetiologies surgical treatment led us to perform closure of gastro-duodenal perforation [27], to remove a necrotic organ (gall bladder, spleen) [15], to drain a collection of pus, to resect a necrotic intestinal segment with immediate anastomosis or bowel exteriorisation in the form of ileostomy or colostomy. We didn't performed planed staged laparotomy unlike Donenik et al. who performed it to treat $10 \%$ of their patients [15].

\section{Post-operative outcome}

The postoperative morbidity was $53.5 \%$, which is higher than the $41 \%$ and $31.5 \%$ rate reported respectively by Seiler et al. [23] and chichom et al. [9] but closed to the $50 \%$ morbidity reported by Doklestić et al. [15]. Wound infection was the commonest postoperative complication as it occurred in 146 patients. It is the most reported postoperative complication of patient with peritonitis [13] [18] [19] [23] [24] [25] [26]. Wound infection can result in postoperative evisceration as it has been noticed 19 times in this study, that is $13 \%$ of the complications and is two fold the findings of Agbakwuru et al. [20], six fold the findings of Yadav et al. [19] and ten fold that's of Dobenick et al. [15]. Intra abdominal abscess was noticed in 31 patients; it was either localized (subphrenic abscess $\mathrm{n}=$ 6) or generalized (postoperative peritonitis $n=25$ ). Subphrenic abscess can be due to surgeon inability to suppress the source of infection because of an insuffi- 
cient peritoneal lavage or an inadequate peritoneal drainage [6] [24]. Generalized postoperative peritonitis cases were due to anastomotic fistula which can be the consequence of sutures performed under tension or in a septic environment. Some other factors have been reported as related to the morbidity of diffuse peritonitis. One of these factors is the delay before intervention which is considered by many as an important key [28] [29]. Other factors include the source of peritonitis with a higher complication rate for bowel perforations [30] and MPI [10]. The other complications could be avoided by much more rigour in fashioning stoma, early mobilization of patients and thromboprophylaxis. Eigthy patients died, that is a mortality rate of $11 \%$, close to the mortality rate reported by many authors [19] [20] [26] [31]. Sanou et al. reported a high mortality rate of $27 \%$ stating that it was the consequence of delay in consultation poor technical background and limited access to intensive care unit [32]. Recognized mortality factors in this study include age, surgical procedure, MPI greater than 29, ASA greater than II, delay in admission time and multiorgan failure [9]. Deaths were due to postoperative toxi-infectious shock revealing thus difficulties in the effective resuscitation of patients and the total eradication of the infectious site [15]. This also confirms that early recognition and diagnosis, timely surgical intervention, appropriate antibiotics and surgical technique and peri-operative care are important factors that can improve post operative morbidity and mortality [18] [19] [25].

\section{Conclusion}

This study has demonstrated that the spectrum of aetiology of peritonitis in the tropical environment is different from that observed in the western countries. The main poor prognosis factors are delay in the intervention and inadequate therapeutic choices. Proper treatment of infectious (typhoid fever) and parasitic (amoebiasis) diseases can reduce the incidence of peritonitis. An early consultation and an adapted management can reduce the morbidity and mortality rates which still remain high.

\section{Conflicts of Interest}

The authors declare that they have no competing interests.

\section{References}

[1] Gupta, S. and Kaushik, R. (2006) Peritonitis: The Eastern Experience. World Journal of Emergency Surgery, 1, 13. http://www.wje.org/content/1/1/13 https://doi.org/10.1186/1749-7922-1-13

[2] Ofoegbu, C.K., Odi, T., Ogundipe, O., Taiwo, J. and Solagberu, B.A. (2005) Epidemiology of Non-Trauma Surgical Deaths. West African Journal of Medicine, 24, 321-324. https://doi.org/10.4314/wajm.v24i4.28225

[3] Boossha, K., Van Vroohoven, T.J. and Van Der Werken, C. (1999) Surgical Management of Severe Secondary Peritonitis. British Journal of Surgery, 86, 371-377. https://doi.org/10.1046/j.1365-2168.1999.01258.x 
[4] Ohene-Yeboah, M. (2005) Causes of Peritonitis in 1188 Consecutive Adult Patients in Ghana. Tropical Doctor, 35, 84-85. https://doi.org/10.1258/0049475054036788

[5] Pomata, M., Vargiu, N., Martinasco, L., Licheri, S., Erdas, E., Zonza, C., et al. (2002) Our Experience in the Diagnosis and Treatment of Diffuse Peritonitis. Il Giornale di Chirurgia, 23, 193-198.

[6] Duibertret, M., Bouillot, J.L. and Alexandre, J.H. (1999) Péritonites Diverticulaires. Aspects Cliniques, Pronostiques, théRapeutiques. Journal de Chirurgie, 124, 299-303.

[7] Barth, X., Gondin, G., Laroyenne, L., Padet, J.M., Li, H.W., Tissot, E., et al. (1985) Les péritonites primitives généralisées d'origine biliaire de l'adulte. Lyon Chirurgical, 81, 305-309.

[8] Cicciarella, G., Chiarenza, S. and Basile, G. (2003) Peritonitis Secondary to Gastrointestinal Perforations. Minerva Chirurgica, 58, 345-349.

[9] Chichom-Mefire, A., Fon, T.A. and Ngowe-Ngowe, M. (2016) Which Cause of Diffuse Peritonitis Is the Dead Liest in the Tropics? A Retrospective Analysis of 305 Cases from the South-West Region of Cameroon. World Journal of Emergency Surgery, 11, 14. https://doi.org/10.1186/s13017-016-0070-9

[10] Billing, A., Frohlich, D. and Schildberg, F.W. (1994) Peritonitis Study Group. Prediction of Outcome Using the Mannhein Peritonitis Index in 2003 Patients. British Journal of Surgery, 81, 209-2013. https://doi.org/10.1002/bjs.1800810217

[11] Clavien, P.A., Barkun, J., de Oliveira, M.L., Vauthey, J.N., Dindo, D., Schulick, R.D., de Santibañes, E., Pekolj, J., Slankamenac, K., Bassi, C., Graf, R., Vonlanthen. R., Padbury, R., Cameron, J.L. and Makuuchi, M. (2009) The Clavien-Dindo Classification of Surgical Complications: Five-Year Experience. Annals of Surgery, 250, 187-196. https://doi.org/10.1097/SLA.0b013e3181b13ca2

[12] Keats, A.S. (1978) The ASA Classification of Physical Status: A Recapitulation. Anesthesiology, 49, 233-236. https://doi.org/10.1097/00000542-197810000-00001

[13] Harouna, Y.D., Abdou, I., Saidou, B. and Bazira, L. (2001) Les péritonites en milieu tropical: particularités étiologiques et facteurs pronostiques actuels à propos de 160 cas. Médecine d'Afrique Noire, 48, 103-106. http://www.santetropicale.com/Resume/34803.pdf

[14] Bali, R.S., Verma, S., Agarwal, P.N., Singh, R. and Talwar, N. (2014) Perforation Peritonitis and the Developing World. ISRN Surgery, 2014, Article ID: 105492. https://doi.org/10.1155/2014/105492

[15] Doklestić, S.K., Bajec, D.D., Djukić, R.V., Bumbaširević, V., Detanac, A.D. and Detanac, S.D. (2014) Secondary Peritonitis Evaluation of 204 Cases and Literature Review. Journal of Medicine and Life, 7, 132-138.

[16] Doraijajan, L.N., Gupta, S., Suryanarayana Deo, S.V., Chumber, S. and Sharma, L.K. (1995) Peritonitis in India. A Decade's Experience. Tropical Gastroenterology, 16, 33-38.

[17] Idali, B., Miguil, M., Guartit, A., Bouderka, M.A., Abassi, O. and Benaguida, M. (1995) Les péritonites graves par perforations d'ulcères gastro-duodénaux. Médecine d'Afrique Noire, 42, 333-326. https://pascal-francis.inist.fr/vibad/index.php?action=getRecordDetail\&idt=3602051

[18] Sanogo, Z.Z., Camara, M., Doumbia, M.M., Soumaré, L., Koumaré, S., Keïta, S., Koïta, A.K., Ouattara, M.A., Togo, S., Yéna, S. and Sangaré, D. (2012) Digestive Tract Perforations at Point G Teaching Hospital in Bamako. Infectious Diseases of Mali, 27, 19-22.

[19] Yadav, D. and Garg, P.K. (2013) Spectrum of Peritonitis in Dheli: 77 Cases Expe- 
rience. Indian Journal of Surgery, 75, 133-137.

https://doi.org/10.1007/s12262-012-0609-2

[20] Agbakwuru, E.A., Adesunkanmi, A.R., Fadiora, S.O., Olayinka, O.S. and Aderonmu, A.O. (2003) A Review of Typhoid Perforation in a Rural African Hospital. West African Journal of Medicine, 22, 22-25. https://doi.org/10.4314/wajm.v22i1.27973

[21] Sharma L, Gupta Soin AS, Sikora S, Kapoor V (1991) Generalised peritonitis in India; the tropical spectrum. The Japanese Journal of Surgery, 21, 272-277. https://doi.org/10.1007/BF02470946

[22] Lebeau, R., Diané, B., Brouh, Y., Kouamé, E.K. and Boua, N. (2010) Péritonites aigues diffuses secondaires non traumatiques: étiologies et évolution après traitement au CHU de Bouaké (RCI). Journal Maghrébin d'anesthésie Réanimation et de Médecine d'Urgence, 17, 200-204.

[23] Seiler, C.A., Brugger, L., Forssmann, U., Baer, H.U. and Buchler, M.W. (2000) Conservative Surgical Treatment of Diffuse Peritonitis. Surgical, 127, 178-184. https://doi.org/10.1067/msy.2000.101583

[24] Mihmanli, M., Agca, B., Altinli, E. And Dinc, M. (2002) Importance of Source Control in Secondary Peritonitis. Turkish Journal of Trauma and Emergency Surgery, 8 , 49-52.

[25] Jhobta, R.S., Attri, A.K., Kaushik, R., Sharma, R. and Jhobta, A. (2006) Spectrum of Perforation Peritonitis in India-Review of 504 Consecutive Cases. World Journal of Emergency Surgery, 1, 26. http://www.wjes.org/content/1/1/26 https://doi.org/10.1186/1749-7922-1-26

[26] Afridi, S.P., Malik, F., Ur-Rahman, S., Shamim, S. and Samo, K.A. (2008) Spectrum of Perforation Peritonitis in Pakistan: 300 Cases Eastern Experience. World Journal of Emergency Surgery, 3, 31. http://www.wjes.org/content/3/1/31 https://doi.org/10.1186/1749-7922-3-31

[27] Alamowitch, B., Aouad, K., Sellam, P., Fourmestraux, J., Gasne, P., Bethoux, J.P., et al. (2000) Traitement laparoscopique de l'ulcére duodenal perforé. Faisabilité et résultats. Gastroentérologie Clinique et Biologique, 24, 1012-1017.

[28] Gedik, E., Girgin, S., Taçyildiz, I.H. and Akgün, Y. (2008) Risk Factors Affecting Morbidity in Typhoid Enteric Perforation. Langenbeck's Archives of Surgery, 393, 973-977. https://doi.org/10.1007/s00423-007-0244-8

[29] Ugochukwu, A.I., Amu, O.C. and Nzegwu, M.A. (2013) Ileal Perforation Due to Typhoid Fever Review of Operative Management and Outcome in an Urban Centre in Nigeria. International Journal of Surgery, 11, 218-222. https://doi.org/10.1016/j.ijsu.2013.01.014

[30] Ngowe Ngowe, M., Touré, A., Mouafo Tambo, F.F., Chichom, A., Tchounzou, R., Ako-Egbe, L. and Sosso, M. (2014) Prevalence and Risk Factors Associated with Post-Operative Infections in the Limbe Regional Hospital of Cameroon. The Open Surgery Journal, 8, 1-8. https://doi.org/10.2174/1874300501408010001

[31] Agarwal, N., Saha, S., Srivastava, A., Chumber, S., Dhar, A. and Garg, S. (2007) Peritonitis: 10 Years Experiences in a Single Surgical Unit. Tropical Gastroenterology, 28, 117-120.

[32] Sanou, D., Sanou, A. and Kafando, R. (1998) Les perforations iléales d'origine typhique difficultés diagnostiques et thérapeutiques à propos de 239 cas. Burkina Médical, 1, 17-20. 